\title{
Home assessment of activities of daily living in patients with severe chronic obstructive pulmonary disease on long-term oxygen therapy
}

\author{
A.A. Okubadejo*, L. O'Shea*, P.W. Jones**, J.A. Wedzicha*
}

Home assessment of activities of daily living in patients with severe chronic obstructive pulmonary disease on long-term oxygen therapy. A.A. Okubadejo, L. O'Shea, P.W. Jones, J.A. Wedzicha. COERS Journals Ltd 1997.

ABSTRACT: In patients with severe chronic obstructive pulmonary disease (COPD) using long-term oxygen therapy (LTOT), few studies have investigated activities of daily living (ADL). We examined the relationships between ADL, quality of life, mood state and airways obstruction in patients using long-term oxygen therapy (LTOT) and in patients not requiring LTOT.

We studied 23 patients (14 males, 9 females; median age 71, range 60-84 yrs) with COPD who received LTOT using oxygen concentrators (LTOT group). We also studied a control group of 19 patients (14 males, 5 females; median age $\mathbf{7 2}$, range 62-75 yrs) with COPD but without severe hypoxaemia (non-LTOT group).

We found no significant difference between groups in health status using the St George's Respiratory Questionnaire (SGRQ). Median Nottingham Extended Activities of Daily Living (EADL) total scores were: LTOT group 10, non-LTOT 17; $(p=0.01)$. Significant correlations $(p<0.001)$ with Nottingham EADL score were found for Hospital Anxiety and Depression (HAD) score (rho=0.59), SGRQ Total score $(r h o=0.65)$ and percentage predicted forced expiratory volume in one second (FEV1) $($ rho=0.66).

In conclusion, in patients with severe chronic obstructive pulmonary disease and broadly similar health status, those using long-term oxygen therapy were less independent in activities of daily living than those not requiring long-term oxygen therapy. Reduced independence in activities of daily living is, however, associated with the extent of airflow limitation, depression and poor health status, and does not, therefore, appear to be simply a result of restriction in movements imposed by the stationary device.

Eur Respir J 1997; 10: 1572-1575.
*Respiratory Care Unit, London Chest Hospital, London, UK. ** Division of Physiological Medicine, St George's Hospital Medical School, London, UK.

Correspondence: A.A. Okubadejo Dept of Medicine for the Elderly Homerton Hospital

Homerton Row London E9 6SR UK

Keywords: Activities of daily living chronic obstructive pulmonary disease oxygen therapy

Received: September 171996 Accepted after revision February 181997

This study was supported by a grant from the South Essex Postgraduate Medical Education and Research Trust.
Patients with chronic obstructive pulmonary disease (COPD) experience disabling breathlessness resulting in reduced exercise capacity [1]. Health status is reduced in patients with COPD [2], and in severe hypoxaemia this is related to the arterial oxygen tension $\left(\mathrm{Pa}_{\mathrm{a}} \mathrm{O}_{2}\right)$ [3]. In patients with severe hypoxaemia, survival can be improved by the use of long-term oxygen therapy (LTOT) $[4,5]$. It has been suggested that the use of LTOT with a stationary source of oxygen can adversely affect independence and restrict activities of daily living (ADL) in the home.

Several recent studies have demonstrated the benefit of pulmonary rehabilitation programmes on exercise capacity and on quality of life measures in patients with COPD [6-8]. However, the aim of pulmonary rehabilitation is to increase the independence of patients in $\mathrm{ADL}$ and to improve health status, rather than to improve performance in laboratory exercise tests. Although previous studies have shown improvement in health-related quality of life, few have investigated the effect of COPD on ADL.

Measurement of ADL is important in the assessment of patients with COPD, especially during pulmonary rehabilitation. Traditionally, ADL measures have been developed for patients with stroke and other severely disabling conditions in the elderly [9]. ADL scales provide a measurement of disability and sometimes of handicap, and are generally used to give some indication of an individual's ability to function independently in daily life. Using one ADL scale (the Nottingham Extended Activities of Daily Living (EADL) scale) we have recently shown that ADL scores in patients with COPD are related to exercise capacity [10], measured using the shuttle walking test [11].

The aim of this study was to assess the ADL of patients with severe COPD, comparing patients with severe hypoxaemic COPD using LTOT provided by oxygen concentrators to patients with severe COPD who did not fit the criteria for LTOT [12].

\section{Materials and methods}

\section{Patients}

Patients were recruited from the chest clinics at the London Chest Hospital. All patients had a diagnosis of 
COPD confirmed by a respiratory physician. Patients had a forced expiratory volume in one second (FEV1) $<1.5$ $\mathrm{L}$ and were all over the age of $60 \mathrm{yrs}$. Patients were excluded if they had clinical evidence of an exacerbation of their COPD within the previous 3 weeks.

\section{Physiological measurements}

Arterial blood gas measurements were made at the clinic visit using arterialized capillary samples from the earlobe [13] while breathing room air. There were 23 patients (14 males and 9 females) using an oxygen concentrator to supply LTOT (DeVilbiss Healthcare UK Ltd, Heston, Middlesex, UK), who had mean (SD) $\mathrm{Pa}, \mathrm{O}_{2}$ $7.3(0.9) \mathrm{kPa}$ and arterial carbon dioxide tension $\left(\mathrm{Pa}, \mathrm{CO}_{2}\right)$ $7.0(1.2) \mathrm{kPa}$. In the comparison group, there were 19 patients (14 males and 5 females) who did not use LTOT, mean (SD) $P \mathrm{a}, \mathrm{O}_{2} 8.7(0.9) \mathrm{kPa}$ and $P \mathrm{a}_{2} \mathrm{CO}_{2} 5.6(0.7) \mathrm{kPa}$.

Both groups of patients were assessed at home with pulse oximetry (Pulsox-7; DeVilbiss Health Care UK Ltd.) and spirometry using a hand-held spirometer (Micro Medical, Chatham, Kent, UK). The patients with LTOT had home assessments performed using supplemental oxygen, but arterial oxygen saturation $\left(\mathrm{Sa}_{\mathrm{a}} \mathrm{O}_{2}\right)$ was also measured after 20 min breathing room air.

\section{Questionnaires}

ADL were assessed using the Nottingham EADL Scale, which is an instrumental ADL measure having 22 items covering four domains of activity (Mobility, Domestic, Kitchen and Leisure); scores range from 0 to 22 and independent persons score high [14]. Health status was assessed using the St George's Respiratory Questionnaire (SGRQ) [15], which is a 76 item, self-completed, disease-specific questionnaire for patients with chronic airflow limitation. This instrument produces three component scores (Symptoms, Activity and Impacts), as well as a Total score. Each of the scores for the SGRQ have a possible range from 0 to 100 , and higher scores indicate poorer health status. Mood state was measured using the Hospital Anxiety and Depression (HAD), scale which has 14 items and produces a score for anxiety and a score for depression $0[16]$. When using the HAD, higher scores indicate higher levels of anxiety or depression and the maximum for each score is 21 ; an individual with a score above $8-10$ is likely to suffer from clinically significant anxiety or depression. Neuropsychological function was assessed using the Reitan Trailmaking test (part A and part B) [17], which is a test of visual scanning, hand-eye co-ordination and mental set flexibility. Slower completion times for the Trailmaking test indicate poorer perception and poorer problem solving. Further information was obtained from the patients using a questionnaire specifically designed for this study, which enquired about use of portable oxygen cylinders and home nebulizers, smoking habit, whether the subject lived alone, whether the subject was housebound, use of equipment or adaptations in the home to aid in daily activities (such as stairlifts, rails or hoists), and, in those using LTOT, the number of hours of daily use of LTOT, and problems encountered using an oxygen concentrator.

The whole assessment took less than $2 \mathrm{~h}$, and the various parts of the assessment were always applied in the same order. Assessments were performed by an experienced respiratory physiotherapist and all took place within the patient's home.

The study received approval from the Ethics Committee of the National Heart and Lung Hospitals and all patients gave informed consent.

\section{Statistical analysis}

Comparisons between the group of patients using LTOT and those not requiring LTOT were made using the Mann-Whitney U-test and Chi-squared tests, where appropriate. Correlations between ADL scores and other variables were measured using Spearman's rank correlations. Statistical significance was accepted at a p-value less than 0.05. A multiple regression analysis model was used to determine the predictors of ADL.

\section{Results}

The characteristics of the patients using LTOT and of the comparison group are shown in table 1. The scores for health status, ADL, mood state and neuropsychological function are presented in table 2.

Table 1. - Characteristics of groups and comparisons between groups

\begin{tabular}{|c|c|c|c|}
\hline & LTOT & Non-LTOT & p-value \\
\hline Age yrs $^{\ddagger}$ & $71(60-84)$ & $72(62-75)$ & NS \\
\hline FEV $1 \%$ pred $^{\#}$ & $28(12)$ & $35(11)$ & $0.023 *$ \\
\hline$P \mathrm{a}, \mathrm{O}_{2} \quad \mathrm{kPa}^{\#}$ & $7.3(0.9)$ & $8.7(0.9)$ & $0.0001 * * *$ \\
\hline$P_{\mathrm{a}, \mathrm{CO}_{2}} \quad \mathrm{kPa}^{\#}$ & $7.0(1.2)$ & $5.6(0.7)$ & $0.0001 * * *$ \\
\hline $\mathrm{Sa}_{\mathrm{a}, \mathrm{O}_{2}} \%^{+\ddagger}$ & $90(64-95)$ & $94(88-98)$ & $0.03 *$ \\
\hline Portable $\mathrm{O}_{2}$ use $\%$ & 35 & 16 & NS \\
\hline Nebulizer use \% & 61 & 53 & NS \\
\hline Housebound \% & 35 & 11 & NS \\
\hline $\begin{array}{l}\text { Use of special } \\
\text { equipment } \%\end{array}$ & 56 & 16 & $0.01 *$ \\
\hline Declared smokers & 17 & 16 & NS \\
\hline
\end{tabular}

¥: median, and range in parenthesis; \#: mean, and SD in parenthesis; ${ }^{+}: \mathrm{Sa}_{\mathrm{a}} \mathrm{O}_{2}$ measured breathing room air. LTOT: long-term oxygen therapy; FEV1: forced expiratory volume in one second; \% pred: percentage of predicted value; $\mathrm{Pa}_{\mathrm{a}} \mathrm{O}_{2}$ : arterial oxygen tension; $P \mathrm{a}, \mathrm{CO}_{2}$ : arterial carbon dioxide tension; $\mathrm{Sa}_{\mathrm{a}} \mathrm{O}_{2}$ : arterial oxygen saturation.

Table 2. - Comparison of quality of life (SGRQ), activities of daily living (Nottingham EADL), anxiety and depression (HAD) and neuropsychological function (Reitan Trail Tests $A$ and $B$ ) between groups

\begin{tabular}{|c|c|c|c|}
\hline & LTOT & Non-LTOT & $\mathrm{p}$-value \\
\hline SGRQ Total ${ }^{\#}$ & $62.7(17.6)$ & $55.4(18.6)$ & 0.21 \\
\hline SGRQ Symptoms" & $66.9(19.5)$ & $69.5(22.0)$ & 0.69 \\
\hline SGRQ Activity\# & $63.1(21.0)$ & $59.2(23.3)$ & 0.57 \\
\hline SGRQ Impacts\# & $62.1(21.5)$ & $52.1(23.9)$ & 0.17 \\
\hline $\begin{array}{l}\text { Nottingham EADL } \\
\text { Total }{ }^{\ddagger}\end{array}$ & $10 \quad(2-20)$ & $17 \quad(6-22)$ & $0.01 *$ \\
\hline HAD Anxiety score & $6 \quad(0-20)$ & $6 \quad(0-15)$ & 0.98 \\
\hline $\begin{array}{l}\text { HAD Depression } \\
\text { score }\end{array}$ & $7 \quad(1-15)$ & $6 \quad(1-13)$ & 0.21 \\
\hline Trail A $s^{\ddagger}$ & $61 \quad(35-149)$ & $47 \quad(33-71)$ & $0.03 *$ \\
\hline Trail B $\mathrm{s}^{\ddagger}$ & $194 \quad(78-493)$ & $125 \quad(71-381)$ & $0.02 *$ \\
\hline
\end{tabular}

\#: mean, and SD in parenthesis; $¥$ : median, and range in parenthesis. EADL: Extended Activities of Daily Living; HAD: Hospital Anxiety and Depression; SGRQ: St George's Respiratory Questionnaire; LTOT: long-term oxygen therapy. 
Table 3. - Rank correlations within the two groups and for both groups combined between Nottingham EADL scores and other variables

\begin{tabular}{llcl}
\hline & $\begin{array}{c}\text { LTOT } \\
(\mathrm{n}=23)\end{array}$ & $\begin{array}{c}\text { Non-LTOT } \\
(\mathrm{n}=19)\end{array}$ & $\begin{array}{c}\text { All } \\
(\mathrm{n}=42)\end{array}$ \\
\hline Age $(\mathrm{yrs})$ & 0.03 & 0.33 & 0.06 \\
FEV $1 \%$ pred $)$ & $0.62^{* *}$ & $0.67^{* *}$ & $0.66^{* * *}$ \\
$\mathrm{~S}_{\mathrm{a}, \mathrm{O}_{2}}(\%)$ & 0.05 & 0.01 & 0.28 \\
$\mathrm{SGRQ}$ & $0.56^{* *}$ & $0.61^{* *}$ & $0.65^{* * *}$ \\
HAD Anxiety & 0.36 & $0.47^{*}$ & $0.38^{*}$ \\
HAD Depression & $0.62^{* *}$ & 0.42 & $0.59^{* * *}$ \\
Reitan Trail A & $0.46^{*}$ & 0.42 & $0.43^{* *}$ \\
Reitan Trail B & $0.50^{*}$ & 0.41 & $0.51^{* *}$ \\
\hline
\end{tabular}

For definitions see legends to tables 1 and 2. Two-tailed significance: $*: \mathrm{p}<0.05 ; * *: \mathrm{p}<0.01 ; * * *: \mathrm{p}<0.001$.

Correlations between ADL and other measures are shown in table 3 . When considering both the LTOT group and the non-LTOT group together, the Nottingham EADL Total score was significantly related to the percentage of predicted FEV1 $($ rho $=0.66 ; p<0.001)$ as shown in figure $1 \mathrm{a}$, and HAD depression score (rho= $0.59 ; \mathrm{p}<0.001)$ as shown in figure $1 \mathrm{~b}$. Variables showing a significant correlation $(\mathrm{p}<0.05)$ with Nottingham EADL score were entered into a multiple regression analysis. The model accounted for $71 \%$ of the variance in Nottingham EADL score. The variables found to be significant covariates of Nottingham EADL score were percentage predicted FEV1 $(p=0.007)$, HAD depression score $(p=$ 0.012), and SGRQ Total score ( $\mathrm{p}=0.02)$.

In the LTOT patients the mean (SD) reported hours of daily use was 17.1 (5.2) h.
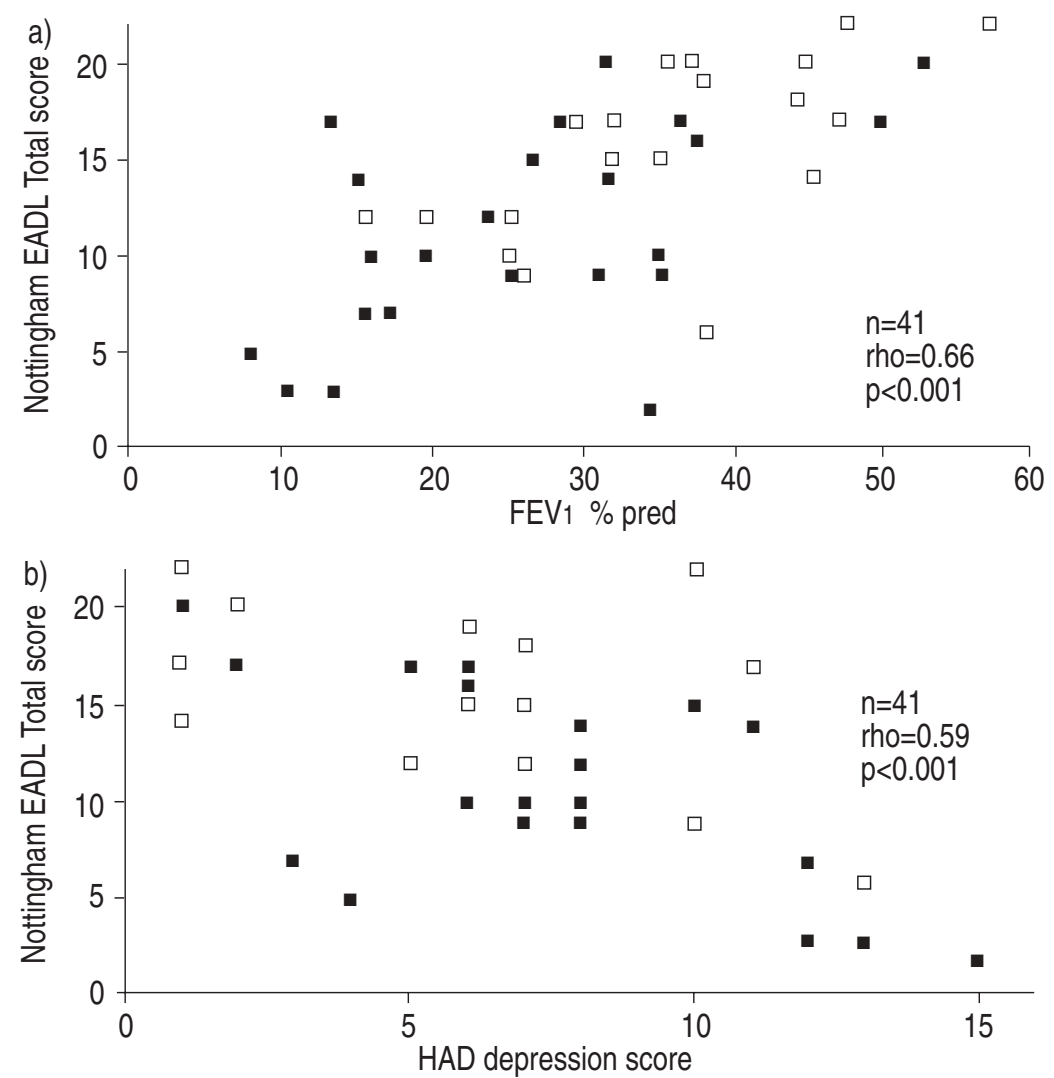

Fig. 1. - a) forced expiratory volume in one second (FEV1) as percentage predicted (\% pred), and b) the relationship betweeen Nottingham Extended Activities of Daily Living (EADL) score and Hospital Anxiety and Depression (HAD) score. a: long-term oxygen therapy (LTOT) group; 口: non-LTOT group.

\section{Discussion}

One of the main aims of therapy in patients with severe COPD is to promote independence in the activities of daily living, though ADL measures have rarely been used in this patient group. Broadly speaking, ADL measures fall into two categories: primary and secondary ADL. Primary ADL are those activities concerned with primary biological functions (e.g. eating, elimination) and are relevant mainly to institutionalized elderly patients. Secondary or instrumental ADL involve more applied activities, and include some elements of the concept of handicap. The instrumental ADL scales are more relevant to patients living in the community rather than in institutions. Activities of daily living have been studied previously in COPD patients using the list of daily activities [18], but this ADL instrument had not been validated in COPD patients. There is no conceptual reason why ADL instruments should not be used in patients with COPD, and we have previously found that the Nottingham EADL scale, a secondary ADL measure, is valid for use in COPD patients [10].

This study shows that, in patients with severe COPD, independence in ADL is related to degree of airflow limitation, health status and mood state. The patients using LTOT were significantly less independent in ADL than the control group. A possible explanation is that the patients using LTOT had more severe COPD, as suggested by the fact that they had lower FEV1. It could also be suggested that the treatment with LTOT itself restricts daily activities. We found no significant differences between COPD patients using LTOT and those not requiring LTOT in terms of health status measured using the SGRQ, or mood state. This suggests that using LTOT does not adversely affect patients' perceived quality of life or mood state. However, the failure to detect a difference may reflect a type II error, since the numbers in the study are small.

It is interesting that although the LTOT patients had poorer independence in ADL they had similar health status scores, in particular similar SGRQ Activity scores, when compared to patients not requiring LTOT. The finding may be a result of a reduced expectation of physical capacity as the disease progresses, and to the fact that patients' expectations may be altered by the need to use a physical device for long periods of the day in order to maintain their health. Alternatively, the construction of the questionnaires may be the reason for the difference in ability to discriminate between the two groups. Many patients in this study were housebound or nearly housebound. The SGRQ Activity scale contains only a few items solely concerned with activities within the home, whereas most of the items in the Notting-ham EADL are based on domestic activities, which are limited in patients with severe COPD.

It is known that neuropsychological function is impaired in hypoxaemic COPD, 
and the degree of impairment is related to the degree of hypoxaemia [19]. Previous studies have shown that oxygen therapy can reverse this impairment [20, 21]. However, in the present study, the LTOT group did not achieve normal neuropsychological function test results nor did they perform as well as the control group. This suggests that any improvement in neuropsychological function that may occur after treatment with oxygen is not a large effect. Anxiety and depression were not adversely affected by the use of LTOT in this study, although previous studies have shown that mood state is significantly related to health status in patients with severe COPD [15, 22]. Depression was related to loss of independence in ADL, which is further evidence for the complex interplay between breathlessness, exercise limitation, depression and anxiety, muscle wasting, quality of life and disability, which has been described previously in these patients [23].

This study was conducted in the patient's home, enabling us to recruit severely disabled patients, who would probably have declined participation in a hospital-based study. It is also possible that the confidence engendered by being at home led to more honest completion of the questionnaires. Ideally, in designing this study, we would have compared a group of COPD patients with severe hypoxaemia using LTOT to a group of COPD patients with equally severe hypoxaemia not using LTOT. However, it is not ethical to withhold LTOT from COPD patients with severe hypoxaemia. Therefore, we selected a control group of COPD patients with moderate hypoxaemia. Also although we excluded patients with FEV1 $>1.5 \mathrm{~L}$, we did not strictly match the group of patients using LTOT with the group not using LTOT in terms of FEV1, since it would be difficult to recruit sufficient numbers of patients not requiring LTOT who have the same degree of airflow obstruction as LTOT patients tend to have.

In conclusion, this study shows that patients with chronic obstructive pulmonary disease using long-term oxygen therapy who tend to have more severe airways obstruction are less independent in their activities of daily living than patients with less severe disease. In patients with severe chronic obstructive pulmonary disease, activities of daily living are related to depression and health status. The Nottingham Extended Activities of Daily Living scale is a measure of activities of daily living which appears to be easy to use in this patient group, yielding useful information.

Acknowledgement: The authors would like to thank L. Grayson for her help with this study.

\section{References}

1. Burrows B, Niden AH, Barclay WR, Kasik JE. Chronic obstructive lung disease. 1. Clinical and physiologic findings in 175 patients and their relationship to age and sex. Am Rev Respir Dis 1965; 91: 521-539.

2. McSweeney AJ, Grant I, Heaton RK, Adams KM, Timms RM. Life quality of patients with chronic obstructive pulmonary disease. Arch Intern Med 1982; 142: 473-478.

3. Okubadejo AA, Jones PW, Wedzicha JA. Quality of life in patients with chronic obstructive pulmonary disease and severe hypoxaemia. Thorax 1996; 51: 44-47.
4. MRC Working Party. Long-term domiciliary oxygen in chronic hypoxic cor pulmonale complicating chronic bronchitis and emphysema. Lancet 1981; i: 681-686.

5. Nocturnal Oxygen Therapy Group. Continuous or nocturnal oxygen therapy in hypoxemic chronic obstructive lung disease: a clinical trial. Ann Intern Med 1980; 93: 391-398.

6. Reardon J, Patel K, ZuWallack RL. Improvement in quality of life is unrelated to exercise endurance after out-patient pulmonary rehabilitation. J Cardiopulm Rehabil 1993; 13: 51-54.

7. Wijkstra PJ, Van Altena R, Kraan J, Otten V, Postma DS, Koeter GH. Quality of life in patients with chronic obstructive pulmonary disease improves after rehabilitation at home. Eur Respir J 1994; 7: 269-273.

8. Goldstein RS, Gork EH, Stubbing D, Avendano MA, Guyatt GH. Randomized controlled trial of respiratory rehabilitation. Lancet 1994; 344: 1394-1397.

9. McDowell I, Newell C. Measuring Health: a Guide to Rating Scales and Questionnaires. Oxford, Oxford University Press, 1987.

10. Garnham R, Bestall J, Garrod R, Paul EA, Jones PW, Wedzicha JA. Relationship between laboratory measures of impairment and measures of disturbance of daily living in patients with COPD. Thorax 1995; 50: A55.

11. Singh SJ, Morgan MDL, Scott S, Walters D, Hardman AE. Development of a shuttle walking test of disability in patients with chronic airways obstruction. Thorax 1992; 47: 1019-1024.

12. Department of Health and Social Security. Introduction of oxygen concentrators to the domiciliary oxygen service. London, Department of Health and Social Security, 1985; Health Notice: HN(FP)(85)(35)

13. Pitkin AD, Roberts CM, Wedzicha JA. Arterialised earlobe blood gas analysis: an underused technique. Thorax 1994; 49: 364-366.

14. Nouri FM, Lincoln NB. An extended activities of daily living scale for stroke patients. Clin Rehabil 1987; 1:301-305.

15. Jones PW, Quirk FH, Baveystock CM, Littlejohns P. A self-complete measure of health status for chronic airflow limitation: the St. George's Respiratory Questionnaire. Am Rev Respir Dis 1992; 145: 1321-1327.

16. Zigmund AS, Snaith RP. The Hospital Anxiety and Depression Scale. Acta Psychiatr Scand 1983; 67: 361-370.

17. Boll TJ. The Halstead-Reitan neuropsychology battery. In: Filskov SB, Boll TJ, eds. Handbook of Clinical Neuropsychology. Vol 1. New York, John Wiley \& Sons, 1981; pp. 577-608.

18. Schrier AC, Decker FW, Kaptein AA, Dijkman JH. Quality of life in elderly patients with chronic nonspecific lung disease seen in family practice. Chest 1990; 98: 894-899.

19. Grant I, Heaton HK, McSweeny AJ, Adams KM, Timms RM. Neuropsychological findings in hypoxemic chronic obstructive pulmonary disease. Arch Intern Med 1982: 142: 1470-1476.

20. Krop HD, Block AJ, Cohen E. Neuropsychological effects of continuous oxygen therapy in chronic obstructive pulmonary disease. Chest 1973; 64: 317-322.

21. Heaton RK, Grant I, McSweeney AJ, et al. Psychologic effects of continuous and nocturnal oxygen therapy in hypoxemic chronic obstructive pulmonary disease. Arch Intern Med 1983; 143: 1941-1947.

22. Williams SJ, Bury MR. Impairment, disability and handicap in chronic respiratory illness. Soc Sci Med 1989; 29: 609-616.

23. Jones PW. Quality of life measurement for patients with diseases of the airways. Thorax 1991; 46: 676-682. 